\title{
Forecast of solar power: a key to power management and environmental protection
}

\author{
Shravanth M. Vasisht ${ }^{1} \cdot$ Sheela K. Ramasesha $^{1}$
}

Received: 7 February 2016/Accepted: 21 April 2016/Published online: 17 May 2016

(C) Springer-Verlag Berlin Heidelberg 2016

\begin{abstract}
Power management through the day and through different seasons in the year is a major challenge in cities around the world as the power generation is from a mix of resources. It is difficult to predict, a priori, the yield from renewable resources on a particular day to tune the fossil fuel fired generators leading to less control of atmospheric pollution from these plants. In this paper, we present a model to predict the yield from a solar photovoltaic (SPV) plant based on the weather forecast in the location. This model can be deployed in the management of distributed energy generation system consisting of SPV systems. The deviations of this model from the measured values are $<15 \%$ for most of the days. The methodology adopted in arriving at this model can be used in any location. This model is simple to use as it uses performance data from a SPV plant in a location and the weather forecast data available in the public domain. Hence, it would be a powerful tool for private solar power producers availing net-metering facility.
\end{abstract}

Keywords Prediction of yield - Solar photovoltaic system · Multivariate regression $\cdot$ Power management

\section{Introduction}

The performance of a solar photovoltaic (SPV) system depends on the solar radiation flux which is a function of many sitespecific factors such as latitude, season, cloudiness and air pollution. It is difficult to foretell, a priori, the yield from SPV

Sheela K. Ramasesha

sheela@caos.iisc.ernet.in

1 Divecha Centre for Climate Change, Indian Institute of Science, Bangalore 560012, India parks at a location. Hence a detailed analysis of the performance of SPV systems is needed to provide valuable information for predicting the yield from such systems.

The yield from a SPV module also depends directly on their photo-conversion efficiency. The efficiencies of the modules depend on the module temperature. The efficiency of the modules with cooling was $13 \%$, while for the modules without cooling it was $10 \%$ (Conserval Engineering Inc. 2015). This kind of cooling will occur in different seasons in a year and the yield from the SPV systems changes accordingly. The performance evaluation of a SPV system in South Eastern Italy, with monocrystalline silicon panels (Congedo et al. 2013), indicates the highest and lowest efficiencies of 17 and $15 \%$ in spring and summer, respectively.

In Germany, the electricity mix comes from sources like coal, nuclear, gas, wind, solar, biomass and hydro-power stations (Fraunhofer Institute for Solar Energy 2014). Since electricity is generated from multiple sources, there is, at times, wastage because all sources feed into the same grid a certain planned amount of electricity which could surpass the demand. The electricity demand varies through the day, week and year (Gridwatch 2015) (Energy Institute of Haas 2015) as seen in the UK Gridwatch. Here also, electricity is generated from multiple sources like coal, nuclear, combined cycle gas-turbine (CCGT), wind, biomass and others. In addition, UK imports electricity from neighbouring countries. In a day, from mid-night to mid-day, there is an increase in demand of almost $49 \%$. This variation in demand is met by mainly increasing production from coalfired and CCGT stations. Similar situation is faced by California electricity demand and supply (California Energy Commission 2015).

Most of the countries are slowly moving towards seeking sustainable energy production and reduction of greenhouse 
gas (GHG) emission (Panwar et al. 2010). Hence, renewable energy sources (RES) play a very important role in distributed energy generation (DEG). Although low emission power generation is possible through RES, they are capital intensive and fluctuating in nature. Practically, a sudden or a complete departure from fossil fuels is not possible (Priya and Bandyopadhyay 2013) and hence, the RES remain as a subsidiary for the conventional energy sources which are mainly powered by fossil fuels. The power demand at a location will be a mix of power from many resources (Ho et al. 2013) which can be represented as

$P=a P_{\mathrm{F}}+b P_{\mathrm{S}}+c P_{\mathrm{W}}+d P_{\mathrm{O}}$,

where $P_{\mathrm{F}}, P_{\mathrm{S}}, P_{\mathrm{W}}$ and $P_{\mathrm{O}}$ are the installed capacities of fossil fuel fired plants, solar installations, wind parks and other sources like CCGT or imports, respectively. $a, b$, $c$ and $d$ are the percentage utilizations that are needed to meet the power demand. When $b$ and $c$ are high, $a$ and $d$ could be reduced, decreasing the polluting gases.

There is a serious problem of finding ways to meet the energy needs consistently without wastage. SPV systems are dependent on environmental variables outside of human control and there is no way to generate more or less electricity based on demand, unless SPV systems are partially shut down when there is excess electricity generation. Hence, it is very essential to forecast the yield of SPV systems. It is highly beneficial because it assists the utility in unit commitment analysis, reserve requirement estimation, contingency analysis, framing electricity bidding strategies and solving voltage issues that arise from grid integration of SPV system (Zhang et al. 2015b). Prediction models were developed for forecasting power output of SPV systems, which played a major role in energy resource management. In 2014, prediction models for power output and energy efficiency were developed using a grid-interactive rooftop photovoltaic (RTPV) system installed on an institutional building located in Macau. These models were validated using measured data of other grid-connected PV systems of Macau. One of the prediction models used for system efficiency was based on the ratio of the predicted output power to the predicted solar irradiance. This ratio model was able to fit the intermediate phase ( 9 a.m. to 4 p.m.) very well but not accurate for the growth and decay phases (Su et al. 2012).

In 2013, a study conducted on a PV installation located in Belgium, consisting of four different technologies, monocrystalline, polycrystalline, micro amorphous and monomorphic SPV modules, proved that module temperature is majorly affected by ambient temperature and irradiation. A mathematical expression was derived to predict the yield on DC side of SPV systems. This expression takes into account, the area per $\mathrm{kW}_{\mathrm{p}}$ of $\mathrm{SPV}$, solar irradiance, transmission-absorption factor, module temperature and temperature coefficient at maximum power point. This model had a maximum deviation of $15 \%$ from the measured values. According to this study, module temperature is less affected by wind temperature, wind velocity and humidity (Verhelst et al. 2013).

A study conducted on a zero energy building (ZEB) of Singapore, with installed SPV capacity of $190 \mathrm{~W}_{\mathrm{p}}$ concluded that polycrystalline type of SPV is the most productive variety of all PV technologies for SPV installations under tropical climate. The annual average daily performance profile of this SPV system was modelled using one of the popular simulation tools and the most accurate model was then used to forecast the annual energy yield under different scenarios. This model fairly predicted the annual average output power of modules. This study also concluded that precision of the model can be improved by taking the energy losses in the module into account and usage of more realistic weather data (Saber et al. 2014).

There are several open-web tools which predict the power output of SPV systems installed at any location. These tools use historic data of power generation and weather of a specific location to predict the SPV output (Iyengar et al. 2014). The concept of artificial neural networks and fuzzy logic has facilitated development of forecast models for incident solar radiation and solar power output. The error in the results obtained from these models was found to be less than the conventional models, mainly due to their capability in depicting behaviour of non-linear and time-varying inputs such as meteorological parameters (Chen et al. 2013; Hocaoglu et al. 2008; Paoli et al. 2010). Although these models are good, they are complex. Hence, it would be much beneficial to adopt a hybrid model which involves the major parameters which cause attenuation of solar radiation at upper atmosphere and solar power output at module level. Net-metering mechanism at household level being the recent trend in developing countries (Mer et al. 2015; Thakur and Chakraborty 2015), it is important to arrive at a forecast model which can be conveniently used by the endusers also. This model must deliver the yield of an SPV system using the forecast data available on public domain and must be simple to use.

In this paper, we establish an empirical relationship between the yield of a SPV system and the atmospheric conditions, based on the performance of a grid-interactive $20 \mathrm{~kW}_{\mathrm{p}}$ SPV system with polycrystalline silicon PV modules installed at a location in tropical belt of India. The power generation patterns from the SPV system during various seasons corresponding to changes in weather conditions are studied. Using multivariate regression, a best fit expression is obtained which can predict, in advance, the expected yield from a SPV system given the weather conditions. The effect of climatic parameters such as cloud cover fraction, aerosol optical depth, humidity and ambient temperature were analysed and accordingly used to predict the yield of the SPV system. The predictions of this nature 
are useful in management of power systems consisting of multiple resources. In many parts of the world, power supply to towns and cities comes from multiple sources. If the yield from SPV systems is known in advance, the generation from coal-fired thermal stations can be moderated and thus control the emissions into the atmosphere.

\section{Experimental details}

An SPV system of capacity $20 \mathrm{~kW}_{\mathrm{p}}$ was commissioned in April, 2013. The system partially powers the Main Administrative Building of Indian Institute of Science which is over 100-year old and is identified as a Heritage Site. Ariel view and single-line diagram of the SPV system are as shown in Fig. 1a, b. The SPV modules are oriented towards the south with an inclination of $13^{\circ}$, which is the latitude of the location. A remote monitoring system records the real-time data. The global horizontal irradiance (GHI), power output and module temperature data are collected at an interval of $5 \mathrm{~min}$. The weather data are collected using Davis Vantage Pro2 weather station.

\section{Results and discussion}

\section{Performance of the SPV system}

The monthly yield of the SPV system during 2013-2014 is shown in Fig. 2a. The highest monthly yield was in March $(3132 \mathrm{kWh})$ and the least in July $(1579 \mathrm{kWh})$ corresponding to summer and monsoon months, respectively.

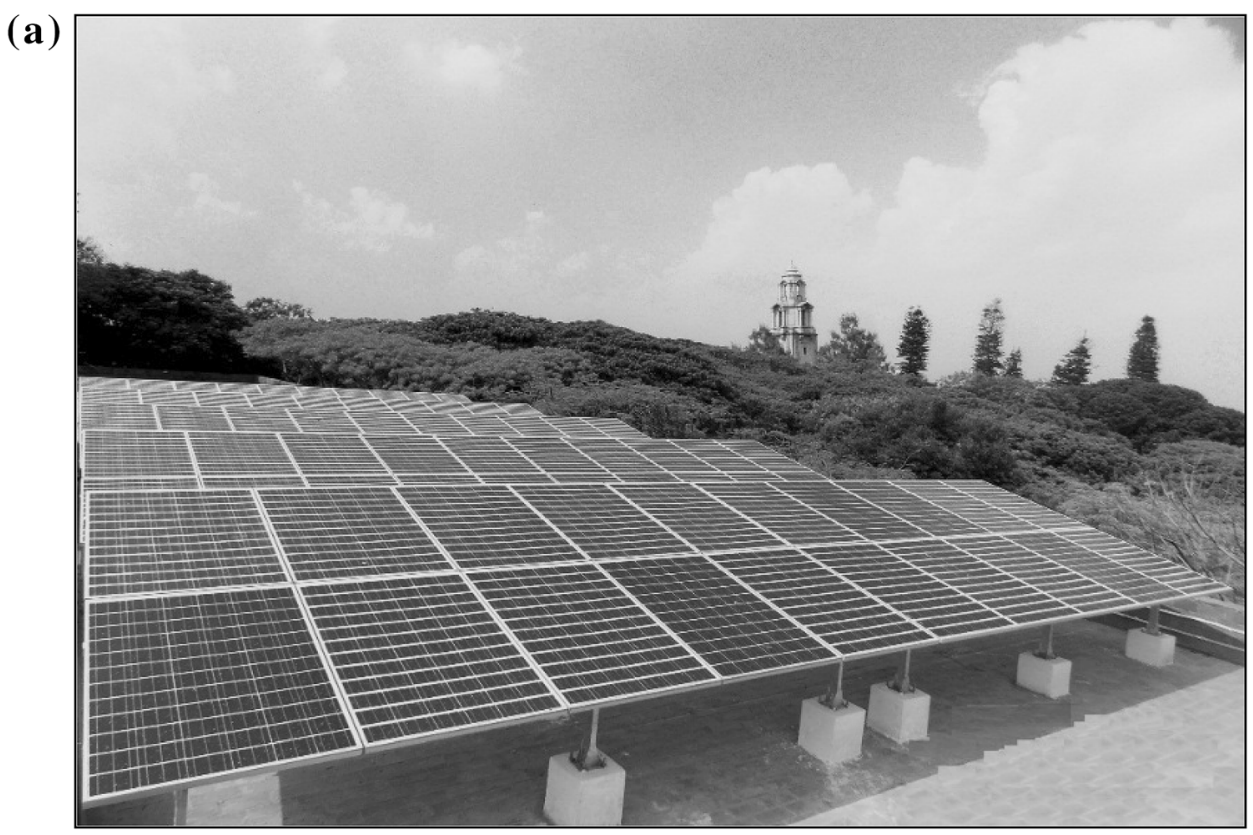

(b)
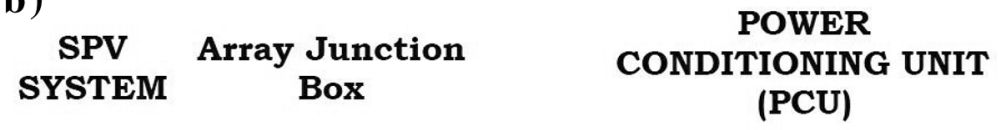
Control Panel

LOAD

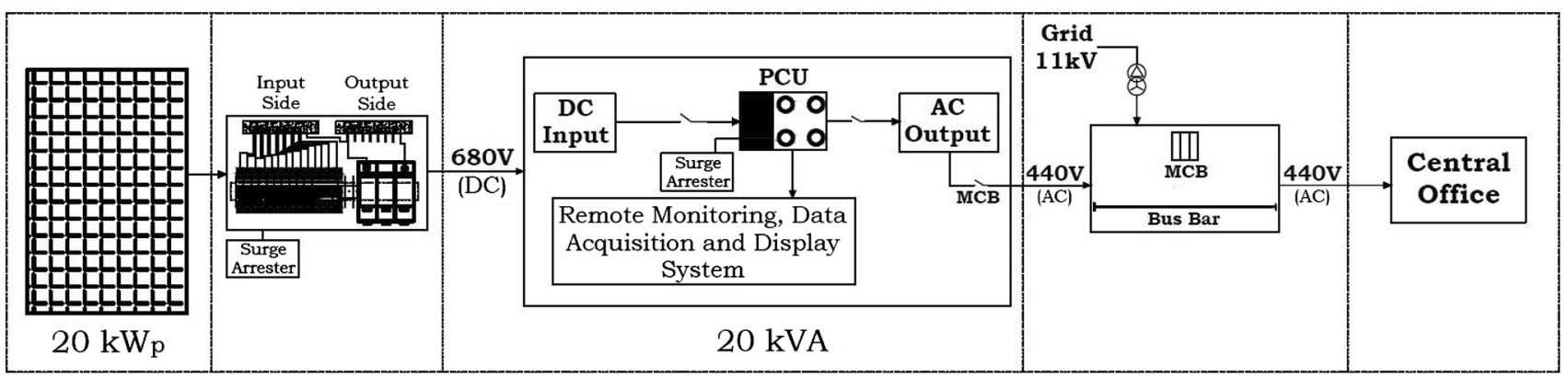

Fig. $120 \mathrm{~kW}_{\mathrm{p}}$ grid-interactive SPV system. a Ariel view of the SPV system. b Single-line diagram of the SPV system connected to the load through a power conditioning unit (PCU) of rating $20 \mathrm{kVA}$ 


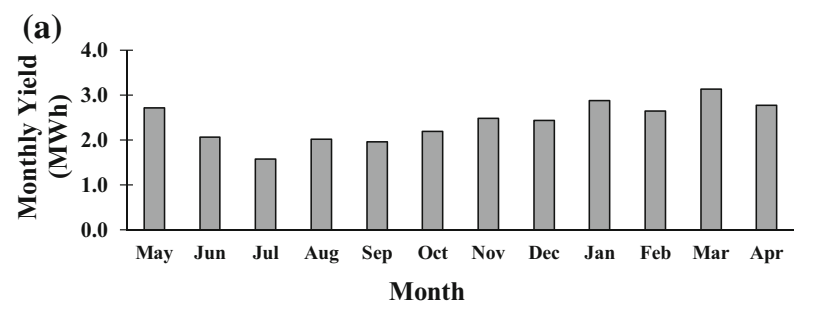

(b)

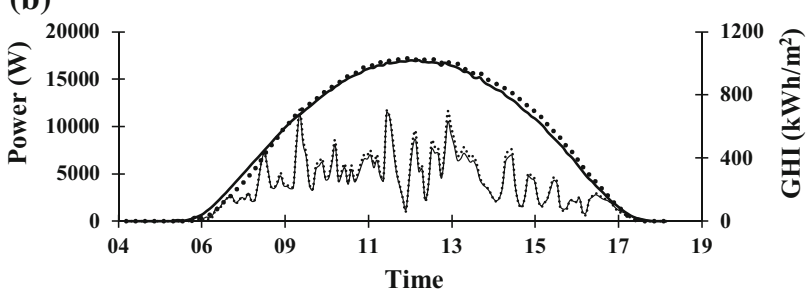

Fig. 2 Generation patterns of the SPV system. a Variation of monthly yield. b Variation of power as a function of time for a clear day (thick line) and a cloudy day (thin line). Dotted line denotes GHI and solid line denotes power generated

The net annual yield during this period was 28.9 MWh and has avoided 23 tonnes of $\mathrm{CO}_{2}$ emission into the atmosphere in 1 year, assuming $\mathrm{CO}_{2}$ emission to be $800 \mathrm{~g}$ per $\mathrm{kWh}$ for a coal-fired thermal plant (Reichelstein and Yorston 2012).

The variation of power generated by the SPV system during the day is plotted in Fig. 2b, along with the instantaneous GHI $\left(I_{\mathrm{i}}\right)$ for a clear sunny and a cloudy day. The power generated follows the variation in $I_{\mathrm{i}}$. The capacity utilization factor (CUF) is an indicator of the overall performance of the SPV system. The CUF of a SPV system is the ratio of actual energy generated in a day to the energy generated if the system works $24 \mathrm{~h}$ a day (Bridge to India 2015). CUF of this SPV system is $16.5 \%$ that is well within the range of average CUF of the rooftop SPV systems in India, which is 16-17\% (National Renewable Energy Laboratory 2011). CUF is location dependent. For instance, the average CUF of SPV system located in Arizona, USA is $24 \%$, whereas in Massachusetts, USA, it is $18 \%$ (Treehugger 2013). A photovoltaic park of capacity 171.36 $\mathrm{kW}_{\mathrm{p}}$ installed in Sitia, Crete has a CUF of $15.26 \%$ (Kymakis et al. 2008). The CUF of the system is mainly dependent on the $\mathrm{GHI}$ at the location and energy conversion efficiency of the SPV modules. GHI at the surface depends on the cloud fraction and atmospheric constituents, mainly humidity and aerosols.

\section{Climatic parameters}

\section{Cloud cover fraction}

The cloud cover fraction (CF) is a very important criterion in the selection of location for a SPV system. The clouds reflect large fraction of the solar radiation back into the space and reduces the transmitted solar radiation that reaches earth's surface (Ramanathan et al. 1988). In the
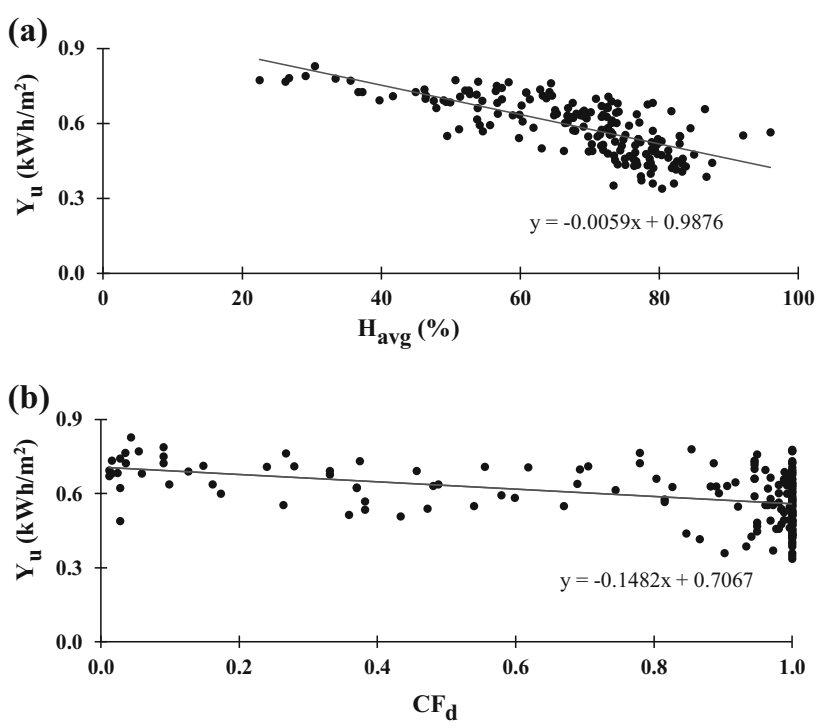

Fig. 3 Variation of $Y_{\mathrm{u}}$ corresponding to $\mathrm{CF}_{\mathrm{d}}$ and $H_{\mathrm{avg}}$. a $Y_{\mathrm{u}}$ as a function of $\mathrm{CF}_{\mathrm{d}}$ for the day taken from MODIS/Aqua satellite. b Variation of $Y_{\mathrm{u}}$ with $H_{\mathrm{avg}}$

presence of clouds, direct component of solar radiation tends to decrease, while diffuse component increases depending on the optical thickness of the cloud (Pfister et al. 2003). The simple equations to calculate the effect of $\mathrm{CF}$ on incident solar radiation found in the literature (Molg et al. 2008) are insufficient to explain radiation loss in the atmosphere. Daily average $\mathrm{CF}\left(\mathrm{CF}_{\mathrm{d}}\right)$ data are available from MODIS/Aqua satellite over $10 \mathrm{~km}^{2}$ area around Bangalore (Earth Observation 2014). The $\mathrm{CF}_{\mathrm{d}}$ thus obtained is plotted against the yield per unit area $\left(Y_{\mathrm{u}}\right)$ of a day from the SPV system in Fig. 3a. As $\mathrm{CF}_{\mathrm{d}}$ increases, $Y_{\mathrm{u}}$ decreases indicating the reduction in daily GHI $\left(I_{\mathrm{d}}\right)$.

\section{Humidity}

Absorption bands of water vapour occur primarily in nearinfrared regions (Eldridge 1967). In addition, there is scattering and reflection of radiation from the surface of water droplets (Gwandu and Creasey 1995). Thus, humidity in the atmosphere affects the GHI that falls on SPV modules. The daily average humidity $\left(H_{\text {avg }}\right)$, as measured at the location, in winter was $56 \%$, in summer $48 \%$, during post-monsoon $71 \%$ and during monsoon $75 \%$. This seasonal variation in $H_{\text {avg }}$ affects the yield from SPV system. As shown in Fig. 3b, $\mathrm{Y}_{\mathrm{u}}$ decreases with increase in $H_{\mathrm{avg}}$ and there is a strong correlation between these factors.

\section{Aerosols}

Aerosols are minute suspended particles that can block solar radiation. Aerosol optical depth (AOD) data could not be obtained for cloudy days. Even for clear days, there is a 


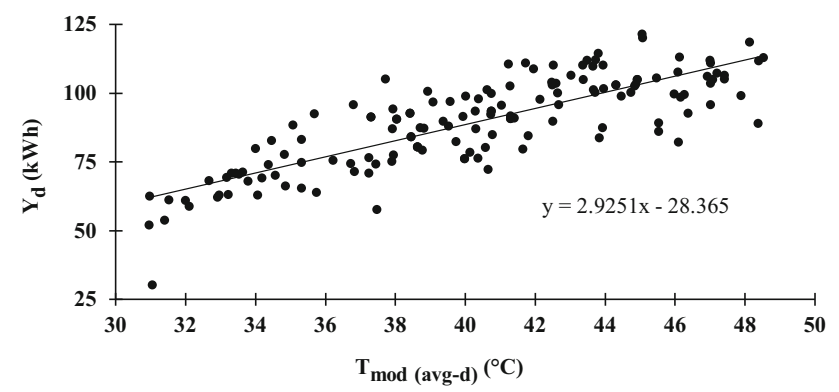

Fig. 4 Variation of $Y_{\mathrm{d}}$ corresponding to $T_{\bmod (a v g-\mathrm{d})}$

large scatter in the data and no correlation between yield and AOD in the location could be established. Hence, the effect of AOD has not been considered in this study.

\section{Module temperature}

One of the necessary conditions for a SPV system to deliver $100 \%$ of its installed capacity is that the temperature of SPV modules and radiation flux are maintained at rated values. The performance of the SPV system is primarily dependent on the module efficiency. As the module operates over a wide range of temperatures throughout the year, its power conversion efficiency is strongly affected by instantaneous module temperature, unless it is maintained at $25{ }^{\circ} \mathrm{C}$ (Nishioka et al. 2003). For a module installed in a field or on the rooftop of a building, the module temperature at which the module attains maximum efficiency varies with seasons and the module efficiency is known to decrease with increase in module temperature (Tina and Scorfani 2008; Vasisht et al. 2016). However, the daily yield $\left(Y_{\mathrm{d}}\right)$ is the summation of power output of the day, which is dependent on solar insolation and module temperature. Figure 4 shows the variation of $Y_{\mathrm{d}}$ corresponding to daily average instantaneous module temperature ( $\left.T_{\text {mod(avg-d })}\right)$. On clear days, the modules attain higher temperatures and the yield is also higher. This shows that module temperature and yield are collectively influenced by prominent climatic variables such as solar irradiance (Ramachandra and Shruthi 2007), albedo (Andrews and Pearce 2013), duration of sunshine (Armstrong and Hurley 2010; Singh and Banerjee 2015), wind, humidity (Mekhilef et al. 2012), precipitation, dust (Darwish et al. 2015), etc. These parameters are season dependent and hence, yield of the SPV system on a particular day is a combination of many factors in addition to module temperature.

\section{Empirical equation}

From this study, it is apparent that long sunshine periods during summer and post-monsoon months produce higher yield, while high ambient temperature in this period reduces the module efficiencies compared to winter and monsoon months. Besides, as already discussed, $Y_{\mathrm{d}}$ of the system is dependent on $\mathrm{CF}_{\mathrm{d}}$ and $H_{\text {avg }}$ in the atmosphere because of their effect on $I_{\mathrm{d}}$. These factors also have a seasonal variation; for instance, the AOD is low, while the $H_{\text {avg }}$ is high during monsoon season. During winters, $I_{\mathrm{d}}$ is low because of shorter days and so are $T_{\bmod (a v g-d)}$. Similarly, during summers, $I_{\mathrm{d}}$ and $T_{\bmod (\text { avg-d) }}$ are high. To understand the influence of various factors on the overall output of a SPV system, a multivariate regression is carried out using the data from the system to come up with a consolidated expression, which is of the form,

Yield $=K+\alpha V_{1}+\beta V_{2}+\gamma V_{3}+\delta V_{4}$,

where $K, \alpha, \beta, \gamma$ and $\delta$ are constants and $V_{1}, V_{2}, V_{3}$ and $V_{4}$ are the variables. The inputs for the regression are $Y_{\mathrm{u}}$, $T_{\text {mod(avg-d) }}, H_{\text {avg }}$, daily extra-terrestrial radiation $\left(\mathrm{ETR}_{\mathrm{d}}\right)$ and $\mathrm{CF}_{\mathrm{d}}$ at the latitude/longitude of the location. $\mathrm{ETR}_{\mathrm{d}}$ at the location was used instead of $I_{\mathrm{d}}$ because ETR $\mathrm{C}_{\mathrm{d}}$ calculations are accurate and are easily available. AOD data for all the days were not available and hence are not considered as a variant in the regression. Twelve days in each month from May 2013 to September 2014 were randomly chosen and the regression equation obtained is

$$
\begin{aligned}
Y_{\mathrm{u}(\mathrm{c})}= & 0.3066-\left(0.01631 * \mathrm{ETR}_{\mathrm{d}}\right) \\
& +\left(0.01515 * T_{\bmod (\text { avg }-\mathrm{d})}\right)-\left(0.001972 * H_{\mathrm{avg}}\right) \\
& -\left(0.0262 * \mathrm{CF}_{\mathrm{d}}\right) .
\end{aligned}
$$

Two other days in each month, which were not considered for regression, were picked for validating the derived equation. The calculated yield $\left(Y_{\mathrm{u}(\mathrm{c})}\right)$ for these days is computed and compared with measured yield $\left(Y_{\mathrm{u}}\right)$, as shown in Fig. 5a. Deviation from this expression for most days is under $15 \%$ and for a couple of days it is as high as $18 \%$. The large error is mostly for a few days with low $\mathrm{I}_{\mathrm{d}}$ due to extreme weather conditions like high $\mathrm{CF}_{\mathrm{d}}$ or $\mathrm{H}_{\mathrm{avg}}$. Accuracy of $\mathrm{CF}_{\mathrm{d}}$ at the location may also add to the deviation in estimating $Y_{\mathrm{u}(\mathrm{c})}$. The deviation is found to be minimum during post-monsoon and early summer periods which may be attributed to clear skies. Figure $5 \mathrm{a}$ also shows the pattern of maximum and minimum $Y_{\mathrm{u}}$ of each month. The variation of maximum $Y_{\mathrm{u}}$ shows the ideal pattern of generation, which would be a function of optimal values of module temperature, humidity and CF, so as to produce the highest possible yields. During the days of post-monsoon and early summer, the values of module temperature, humidity and CF are optimal, thus leading to maximum $Y_{\mathrm{u}}$.

Figure $5 \mathrm{~b}$ shows the calculated and observed yield for January and February 2015, which lies outside the period considered for regression. Only for 3 days, the deviation is found to be over $15 \%$ with maximum deviation of $18.5 \%$ indicating that Eq. (2) holds good for any period of time. 


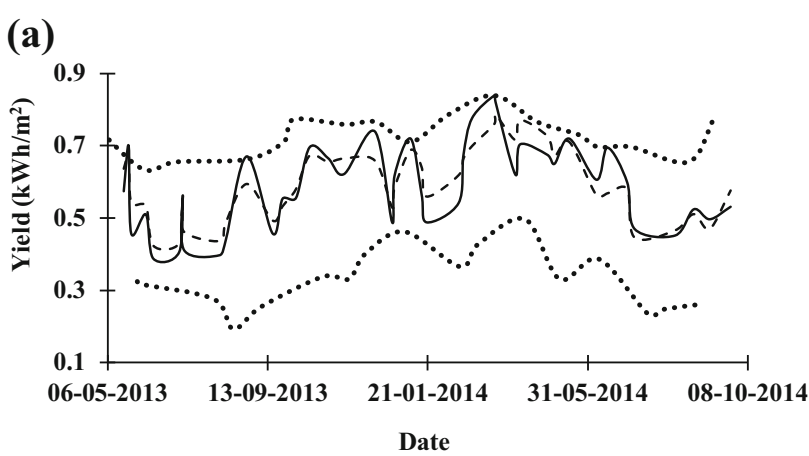

(b)

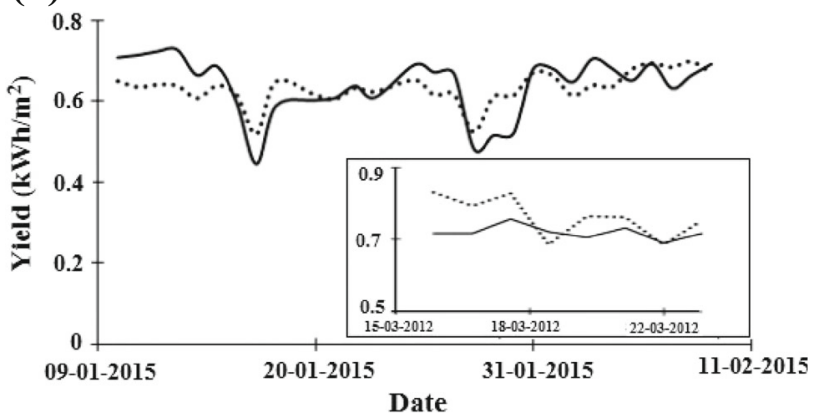

Fig. 5 Regression curve: a $Y_{\mathrm{u}}$ (solid line) and $Y_{\mathrm{u}(\mathrm{c})}$ (broken line). The daily maximum and minimum $Y_{\mathrm{u}}$ in the month are shown by dotted lines. $\mathbf{b} Y_{\mathrm{u}}$ (solid line) and $Y_{\mathrm{u}(\mathrm{c})}$ (dotted line) for January/February 2015. Inset $Y_{\mathrm{u}}$ (dotted line) data from a different SPV system and $Y_{\mathrm{u}(\mathrm{c})}$ (solid line)

One week's data from another SPV system installed in Bangalore that had modules with rated efficiency of $11 \%$ became available. The yield from this plant is scaled with the ratio of the observed average efficiency of the known SPV module and the rated efficiency of the unknown module. The scaled yield and the yield calculated from Eq. (3) are compared in the inset of Fig. 5b. For one day, the deviation is $15 \%$ and for all other days the deviation is under $10 \%$. Thus, it is possible to rewrite Eq. (3) as

$$
\begin{aligned}
Y_{\mathrm{u}(\mathrm{c})}= & {\left[0.3066-\left(0.01631 * \mathrm{ETR}_{\mathrm{d}}\right)\right.} \\
& +\left(0.01515 * T_{\bmod (\mathrm{avg}-\mathrm{d})}\right)-\left(0.001972 * H_{\mathrm{avg}}\right) \\
& \left.-\left(0.0262 * \mathrm{CF}_{\mathrm{d}}\right)\right] *\left(\eta_{\mathrm{RP}} / \eta_{\mathrm{RU}}\right),
\end{aligned}
$$

where $\eta_{\mathrm{RP}}$ is the average efficiency of the reference SPV system and $\eta_{\mathrm{RU}}$ is the rated efficiency of the unknown SPV system.

Most of the countries around the world have weather forecasting models that can predict the atmospheric conditions for about $48 \mathrm{~h}$ quite precisely. In recent times, several models have been developed for forecasting multilevel CF (Shah et al. 2015; Paoli et al. 2015), solar radiation (Pelland et al. 2011), ambient temperature and humidity (Kumar et al. 2015). In addition to these, weather forecasts are available on the public domain, which are normally precise and reliable. Hence, by obtaining data on one SPV installation in a location and deriving an empirical equation of this type, it is possible to predict the yield from any SPV system in that location in advance.

In most of the SPV systems, module temperature is not recorded. On one system if module temperature data are collected, a relationship between $T_{\bmod (a v g-d)}$ and daily average ambient temperature $\left(T_{\mathrm{amb}(\mathrm{avg}-\mathrm{d})}\right)$ can be derived for the location that can be used for prediction. In the present study, $T_{\bmod (\text { avg-d) }}=1.54 * T_{\text {amb(avg-d) }}$ relation fitted the curve and with the calculated $T_{\bmod (a v g-d)}$, only four data points showed a deviation of around $20 \%$. The ratio ( $\left.T_{\text {mod(avg-d) }} / T_{\text {amb(avg-d) }}\right)$ may differ for locations having nontropical climate.

With this kind of prediction, when multiple resources are used for generation of electricity, the power generation from other sources can be tuned for maximum efficiency and minimum pollution. For example, if the weather prediction is clear skies with a specific amount of humidity and CF, the yield from all the SPV systems in that location can be predicted. Based on the weather prediction, even $24 \mathrm{~h}$ in advance, quite a bit of fossil fuel usage can be prevented because the term $b$ in Eq. (1) would be known. There have been many models (Fard et al. 2016; Zhang et al. 2015a) to predict power that can be generated from a wind turbine and hence the term $c$ in Eq. (1) is also known. Thus, the terms $a$ and $d$ can be fine-tuned and the thermal power plants using fossil fuels can be used at minimum levels.

\section{Conclusion}

Power management at a location offers many challenges as it is a mix from different sources and all the power stations end up generating more power than required. There is a huge wastage of power leading to burning fossil fuels unnecessarily. In order to optimize usage of the fossil fuel fired thermal stations, it is important to predict the power generation from other resources like solar and wind plants. To predict the yield from a solar plant, it is shown that the weather conditions play an important role. An empirical relation between climatic conditions (like humidity, CF and temperature) and the yield from an SPV system is derived using data from a $20 \mathrm{~kW}_{\mathrm{p}} \mathrm{SPV}$ system. It is observed that the yield from the SPV system decreases linearly with increase in humidity and CF. The module temperature significantly influences module efficiency.

The forecast model derived can be used in management of distributed energy generation (DEG) system consisting of SPV systems. For most of the clear days, the model provides a minimal deviation $(<15 \%)$ from the measured values and for a few days with randomly changing weather or extreme weather conditions, it is as high as $18 \%$. This 
deviation is quite acceptable as it can be considered for maintaining other power sources as spinning reserve. The methodology used for deriving this model can be adopted at any location to forecast the power output from a SPV plant to tune the power generation from coal or natural gas fired power stations. This model is simple to use, especially for the consumer-end, mainly because it uses the forecast data available on the public domain. The accuracy of this model is dependent on the precision of forecast data available and weather conditions which are favourable for solar power generation.

\section{References}

Andrews RW, Pearce JM (2013) The effect of spectral albedo on amorphous silicon and crystalline silicon solar photovoltaic device performance. Sol Energy 91:233-241. doi:10.1016/j. solener.2013.01.030

Armstrong S, Hurley WG (2010) A new methodology to optimize solar energy extraction under cloudy conditions. Renew Energy 35:780-787. doi:10.1016/j.renene.2009.10.018

Bridge to India (2015) Rooftop revolution: unleashing Delhi's solar potential, New Delhi: Bridge to India. http://www.bridgetoindia. $\mathrm{com} / \mathrm{blog} /$ rooftop-revolution-unleashing-delhis-solar-potential/. Accessed 3 May 2013

California Energy Commission (2015) California electricity data, facts, and statistics. http://energyalmanac.ca.gov/electric. Accessed 3 Sept 2015

Chen SX, Gooi HB, Wang MQ (2013) Solar radiation forecast based on fuzzy logic and neural networks. Renew Energy 60:195-201. doi:10.1016/j.renene.2013.05.011

Congedo PM, Malvoni M, Mele M, Giorgi MGD (2013) Performance measurements of monocrystalline silicon PV modules in Southeastern Italy. Energy Convers Manag 68:1-10. doi:10.1016/j. enconman.2012.12.017

Conserval Engineering Inc. (2015) Solar power wall. http://solarwall. com/en/products/pvthermal.php. Accessed 16 Sept 2015

Darwish ZA, Kazem HA, Sopian K, Goul MAA, Alawadhi H (2015) Effect of dust pollutant type on photovoltaic performance. Renew Sustain Energy Rev 41:735-744. doi:10.1016/j.rser.2014. 08.068

Eldridge RG (1967) Water vapour absorption of visible and near infrared radiation. Appl Opt 6(4):709-713. doi:10.1364/AO.6. 000709

Energy Institute of Haas (2015) What's the point of an electricity storage mandate?. https://energyathaas.wordpress.com/2013/07/ 29/whats-the-point-of-an-electricity-storage-mandate. Accessed 12 July 2015

Fard AK, Khosravi A, Nahavandi S (2016) A new fuzzy-based combined prediction interval for wind power forecasting. IEEE Trans Power Syst 31(1):18-26. doi:10.1109/TPWRS.2015. 2393880

Fraunhofer Institute for Solar Energy Systems (2014) Electricity production from solar and wind in Germany in 2014. https:// www.ise.fraunhofer.de/en/downloads-englisch/pdf-files-englisch/ data-nivc-/electricity-production-from-solar-and-wind-in-germany2014.pdf. Accessed 25 Sept 2015

Gridwatch (2015) UK National Grid Status. http://www.gridwatch. templar.co.uk. Accessed 26 Sept 2015
Gwandu BAL, Creasey DJ (1995) Humidity: a factor in the appropriate positioning of a photovoltaic power station. Renew Energy 6(3):313-316. doi:10.1016/0960-1481(95)00073-S

Ho WS, Hashim H, Lim JS, Klemes JJ (2013) Combined design and load shifting for distributed energy system. Clean Technol Environ Policy 15:433-444. doi:10.1007/s10098-013-0617-3

Hocaoglu FO, Gerek ON, Kurban M (2008) Hourly solar radiation forecasting using optimal coefficient 2-D linear filters and feedforward neural networks. Sol Energy 82:714-726. doi:10.1016/j. solener.2008.02.003

Iyengar S, Sharma N, Irwin D, Shenoy P, Ramamritham K (2014) Demo Abstract: SolarCast-an open web service for predicting solar power generation in smart homes. In: Proceedings of the 1st ACM conference on embedded systems for energy-efficient buildings, vol 14, New York, USA. BuildSys, pp 174-175

Kumar P, Ojha SP, Singh R, Kishtawal CM, Pal PK (2015) Performance of weather research and forecasting model with variable horizontal resolution. Theor Appl Climatol 122:1-9. doi:10.1007/s00704-015-1607-7

Kymakis K, Kalykakis S, Papazoglou TM (2008) Performance analysis of a grid connected photovoltaic park on the island of Crete. Energy Convers Manag 50:433-438. doi:10.1016/j.encon man.2008.12.009

Mekhilef S, Saidur R, Kamalisarvestani M (2012) Effect of dust, humidity and air velocity on efficiency of photovoltaic cells. Renew Sustain Energy Rev 16:2920-2925. doi:10.1016/j.rser. 2012.02.012

Mer S, Dudhe S, Suryawanshi S (2015) Future trends in distributed renewable systems. Int $\mathrm{J}$ Eng Res Electron Commun Eng 2(6):7-10

Molg T, Cullen NJ, Kaser G (2008) Solar radiation, cloudiness and longwave radiation over low-latitude glaciers: implications for mass-balance modelling. J Glaciol 55(190):292-302. doi:10. 3189/002214309788608822

National Renewable Energy Laboratory (2011) 2010 solar technologies market report. http://www.nrel.gov/docs/fy12osti/51847. pdf. Accessed 2 June 2015

Nishioka K, Hatayama T, Uraoka Y, Fuyuki T, Hagihara R, Watanabe M (2003) Field-test analysis of PV system output characteristics focusing on module temperature. Sol Energy Mater Sol Cells 75:665-671

NASA Earth Observation (2014) Aerosol optical thickness-(1 month-Aqua/MODIS), Oct. 24, 2014. http://neo.sci.gsfc.nasa. gov/view.php?datasetId=MYDAL2_M_CLD_FR. Accessed 24 Oct 2014

Panwar NL, Shrirame HY, Bamniya BR (2010) $\mathrm{CO}_{2}$ mitigation potential from biodiesel of castor seed oil in Indian context. Clean Technol Environ Policy 12:579-582. doi:10.1007/s10098009-0269-5

Paoli C, Voyant C, Muselli M, Nivet ML (2010) Forecasting of preprocessed daily solar radiation time series using neural networks. Sol Energy 84:2146-2160. doi:10.1016/j.solener. 2010.08.011

Paoli C, Voyant C, Muselli M, Nivet ML (2015) A 10 year solar radiation forecasting using ad-hoc time series preprocessing and neural networks. Remote Sens 7:7768-7784. doi:10.1007/978-3642-04070-2_95

Pelland S, Galanis G, Kallos G (2011) Solar and photovoltaic forecasting through post-processing of the Global Environmental Multiscale numerical weather prediction model. Prog Photovolt Res Appl 21:284-296. doi:10.1002/pip.1180

Pfister G, McKenzie RL, Liley JB, Thomas A, Forgan BW, Long CN (2003) Cloud coverage based on all-sky imaging and its impact on surface solar irradiance. J Appl Meteorol 42(10):1421-1434. doi:10.1175/1520-0450(2003)042<1421:CCBOAI >2.0.CO;2 
Priya GSK, Bandyopadhyay S (2013) Emission constrained power system planning: a pinch analysis based study of Indian electricity sector. Clean Technol Environ Policy 15:771-782. doi:10.1007/s10098-012-0541-y

Ramachandra TV, Shruthi BV (2007) Spatial mapping of renewable energy potential. Renew Sustain Energy Rev 11:1460-1480. doi:10.1016/j.rser.2005.12.002

Ramanathan V, Cess RD, Harrison EF, Minnis P, Barkstrom BR, Ahmad E (1988) Cloud-radiative forcing and climate: results from the earth radiation budget experiment. Science 243(4887):57-63. doi:10.1126/science.243.4887.57

Reichelstein S, Yorston M (2012) The prospects for cost competitive solar PV power. Energy Policy 55:117-127. doi:10.1016/j.enpol. 2012.11.003

Saber EM, Lee SE, Manthapuri S, Yi W, Deb C (2014) PV (photovoltaics) performance evaluation and simulation-based energy yield prediction for tropical buildings. Energy 71:588-595. doi:10.1016/j.energy.2014.04.115

Shah ASMB, Yokoyama H, Kakimoto N (2015) High-precision forecasting model of solar irradiance based on grid point value data analysis for an efficient photovoltaic system. IEEE Trans Sustain Energy 6(2):474-481. doi:10.1109/TSTE.2014.2383398

Singh R, Banerjee R (2015) Estimation of rooftop solar photovoltaic potential of a city. Sol Energy 115:589-602. doi:10.1016/j. solener.2015.03.016

Su Y, Chan LC, Shu L, Tsui KL (2012) Real-time prediction models for output power and efficiency of grid-connected solar photovoltaic systems. Appl Energy 93:319-326. doi:10.1016/j. apenergy.2011.12.052

Thakur J, Chakraborty B (2015) A study of feasible smart tariff alternatives for smart grid integrated solar panels in India. Energy 93:963-975. doi:10.1016/j.energy.2015.09.100

Tina GM, Scorfani S (2008) Electrical and thermal model for PV module temperature evaluation. In: The 14th IEEE Mediterranean Electrotechnical Conference, 2008, Ajaccio, France, pp 585-590. doi:10.1109/MELCON.2008.4618498

Treehugger (2013) Energy Basics. https://www.academia.edu/ 8361186/Energy_basics. Accessed 12 Sept 2015

Vasisht MS, Srinivasan J, Ramasesha SK (2016) Performance of solar photovoltaic installations: effect of seasonal variations. Sol Energy 131:39-46. doi:10.1016/j.solener.2016.02.013

Verhelst B, Caes D, Vandevelde L, Desmet J (2013) Prediction of yield of solar modules as a function of technological and climatic parameters. In: IEEE international conference on clean electrical power, Alghero, Sardinia, pp 1-6. doi:10.1109/ICCEP.2013. 6586956

Zhang Y, Yang J, Wang K, Wang Z (2015a) Wind power prediction considering nonlinear atmospheric disturbances. Energies 8(1):475-489. doi:10.3390/en8010475

Zhang Y, Beaudin M, Taheri R, Zareipour H, Wood D (2015b) Dayahead power output forecasting for small-scale solar photovoltaic electricity generators. IEEE Trans Smart Grid 6(5):2253-2262. doi:10.1109/TSG.2015.2397003 